\title{
DUCTILE CRACK PROPAGATION WITH THE STRAIN ENERGY DENSITY CRITERION
}

\author{
C. L. CHOW \\ Department of Mechanical Engincering, University of Hong Kong, Hong Kong \\ and \\ XU JILIN \\ Institute of Mechanics, Acadenic Sinica, Beijing, People's Republic of China
}

\begin{abstract}
The strain energy density criterion is used to characterize subcritical crack growth in a thin aluminum alloy sheet undergoing general yielding. A finite element analysis which incorporates both material and geometrical nonlinear behaviors of the cracked sheets is developed to predict fracture loads at varying crack growth increments. The predicted results are in excellent agreement with those measured experimentally. thus confirming the validity of the strain energy density criterion for characterizing ductile crack propagation.
\end{abstract}

\section{INTRODUCTION}

Considerable effort has been devoted in the last decade to the development of ductile fracture characterization capable of successfully predicting design life expectancy of engineering components undergoing gross yielding. While the fracture criterion such as $J$-integral $[1,2]$, COD $[3,4]$ and tearing modulus [5, 6] have received relative popularity [7], there remain many inconsistencies in their respective interpretation of test data extracted from different specimen geometries and modes of loading [8-11]. These inconsistencies have cast doubts on their viability as ductile fracture control parameters. The strain energy density criterion due to Sih [12] has been shown to be capable of characterizing not only brittle [13] but also ductile fractures $[14,15]$.

According to the strain energy density criterion, crack initiation or growth is postulated to occur when the strain energy density $(\mathrm{d} W / \mathrm{d} V)$ in an element ahead of the crack tip along its prospective crack path reaches a critical material resistance parameter $(\mathrm{d} W / \mathrm{d} V)$ ). The parameter is determined from the area underneath a true stress-strain diagram experimentally determined from an uniaxial tensile specimen or using the following expression:

$$
\left(\frac{d W}{d V}\right)_{c}=\int_{0}^{\epsilon_{u}} \sigma d \epsilon,
$$

where $W$ is stored strain energy, $V$ is volume element of the material used, $\epsilon_{u}$ is ultimate strain, $\sigma$ is true stress and $\epsilon$ is true strain. For a structure loaded beyond the elastic range of its material, the irreversible plastic deformation experienced by the structure will induce residual stresses and its associated strain energy will no longer be available for crack initiation or advancing its growth. If a point $p$ along the true stress-strain curve is assumed to have reached beyond the elastic limit, then eqn (1), which may also be regarded as a material resistance parameter to crack growth, should necessarily be modified as

$$
\left(\frac{d W}{d V}\right)_{c}^{*}=\left(\frac{d V}{d V}\right)_{c}-\left(\frac{d W}{d V}\right)_{D},
$$

where $(\mathrm{d} W / \mathrm{d} V)_{\text {, }}$, represents the degree of plastic deformation at the stress $\sigma_{p}$, on a true stressstrain diagram.

The methodology described above has been applied by Sih and Madenci $[14,15]$ recently to predict fracture loads of a thin plate stressed beyond gross yiclding using a finite element method. However, no experimental verification was presented in their analysis to substantiate 
the validity of the strain energy density criterion for ductile crack growth analysis. In addition, no explicit reference was made to highlight the importance of crack surface unloading after each crack advance on its subsequent crack growth behavior.

This paper is intended to examine the validity of the application of the strain energy density criterion to ductile subcritical crack growth in a thin plate undergoing large plastic deformation. Both material and geometrical nonlinearities are included in a finite element formulation which also incorporates crack surface unloading after each incremental crack advance. The predicted fracture loads during a series of subcritical crack growth steps in the thin plate are then compared with those measured experimentally.

\section{Finte element analysis}

In order to take fully into account large elastic-plastic deformation near a crack in the thin plate, an Eulerian finite element formulation capable of characterizing large elastic-plastic flow is chosen. This is based on Hill's variational principle for incremental deformations of isotropically hardening Prandtl-Reuss materials [16]. The formulation of rate equilibrium at any large deformation may be expressed in the form of virtual work equation as [17] as

$$
\int_{v^{\prime}}\left[\tau_{i j}^{*} \delta D_{i j}-\frac{1}{2} \sigma_{i j} \delta\left(2 D_{i k} D_{k j}-v_{k, i} v_{k, j}\right)\right] \mathrm{d} V=\int_{S} \dot{f}_{i} \delta v_{i} \mathrm{~d} S+\int_{V^{\prime}} \dot{b}_{i} \delta v_{i} \mathrm{~d} V
$$

where $V$ is element volume, $\tau_{i j}^{*}$ is Jaumann co-rotational rate of Kirchhoff stress, and $D_{i j}$ is deformation rate. $\{z\}$ is the vector of velocity components, $\tau_{k, i}$ is $\partial v_{k} / \partial x_{i}$ for the position vector $x$ of a material in the current state, $\dot{f}_{i}$ is force vector intensity rate and $\dot{b}$ is body force intensity rate. The velocity vector $\{0\}$ and the deformation rate $\{D\}$ to the rates of degrees of freedom $\{\dot{\psi}\}$ of a mesh representing the current geometry are:

$$
\begin{aligned}
\{x\} & =[N]\{\dot{\psi}\} \\
{[D] } & =[B]\{\dot{\psi}\} .
\end{aligned}
$$

The matrices are expressed as

$$
\left[B_{i j}\right]=\frac{1}{2}\left[N_{i}\right]_{, j}+\frac{1}{2}\left[N_{j}\right]_{i}
$$

An Eulerian finite element rate equilibrium equation based on the virtual work formulation of eqn (3) may be deduced as

$$
[K]\{\psi\}=\{\dot{P}\}
$$

where

$$
\{\dot{P}\}=\int_{V}[N]^{T}\{\dot{b}\} \mathrm{d} V+\int_{S}[N]^{T}\{\dot{f}\} \mathrm{d} S
$$

and

$$
[K]=\left[K_{c^{\prime} p}\right]+\left[K_{s}\right]
$$

for which

$$
\begin{aligned}
{\left[K_{c p}\right] } & =\int_{V}[B]^{T}[C][B] \mathrm{d} V \\
{\left[K_{s}\right] } & =\int_{V^{\prime}}\left[N_{k}\right]_{, i}^{T} \sigma_{i j}\left[N_{k}\right]_{j}-2\left[B_{k i}\right]^{T} \sigma_{i j}\left[B_{k j}\right] \mathrm{d} V .
\end{aligned}
$$

The matrices $\left[K_{c p}\right]$ and $\left[K_{s}\right]$ shown above represent respectively conventional small displacement stiffness matrix and geometrical nonlinear matrix. 
As mentioned earlier, a thin plate embedded with a center crack subjected to an applied stress $\sigma_{0}$ at both upper and lower boundaries (see Fig. 1) was considered in the investigation. Because of the axisymmetrical nature of the specimen geometry and loading, only a quarter of the specimen needs to be discretized. A typical finite element idealization is shown in Fig. 2 whereas Fig. 3 depicts detailed element construction near the crack tip. The finite element analysis was performed utilizing the tangent modulus incremental plasticity or updated Lagrangian and a first-order self-correcting procedure for solution convergence [18].

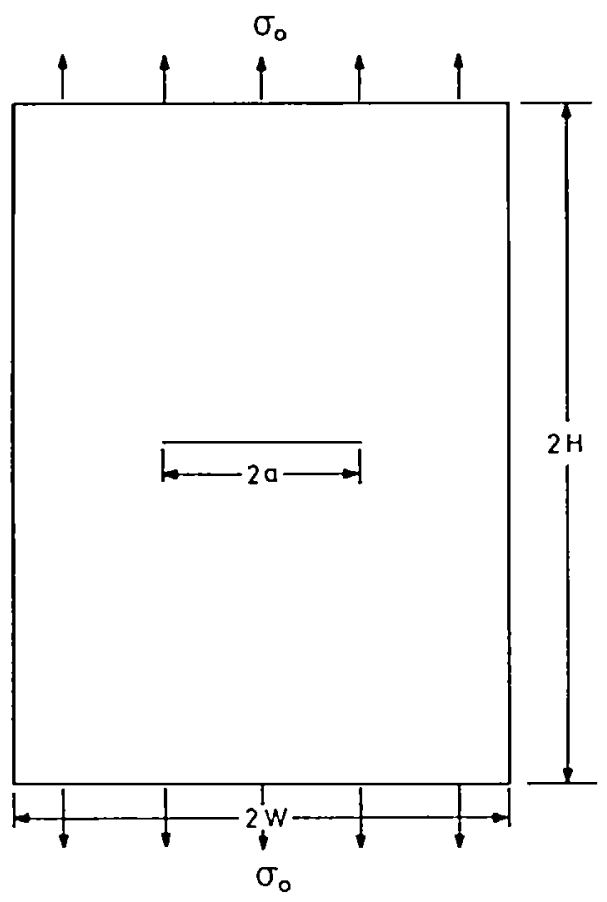

Fig. 1. An inclined crack subject.

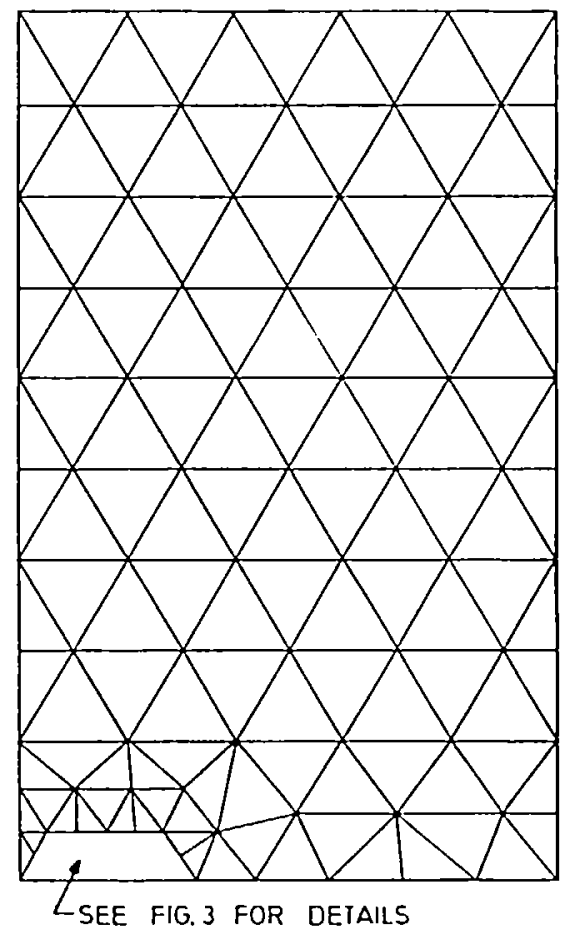

Fig. 2. A typical finite element representation of a center cracked plate. 
Table 1. Mechanical properties

\begin{tabular}{lccccrr}
\hline Material & $\begin{array}{c}\text { Young's modulus, } \\
E(\mathrm{GPa})\end{array}$ & $\begin{array}{c}\text { Yield stress, } \\
\sigma_{y s}(\mathrm{MPa})\end{array}$ & $\begin{array}{c}\text { Ultimate stress, } \\
\sigma_{\| \prime}(\mathrm{MPa})\end{array}$ & $\begin{array}{c}\text { Maximum elongation, } \\
\epsilon_{f}(\mathrm{~mm})\end{array}$ & $\alpha$ & $n$ \\
\hline LY12-CS & 69.48 & 320 & 489 & 0.134 & 0.013 & 5.0 \\
\hline
\end{tabular}

The material chosen for the investigation is aluminum alloy LY12-CS and its mechanical properties are outlined in Table 1. The dimensions selected are $H=94 \mathrm{~mm}, W=55 \mathrm{~mm}$, $a=6.73 \mathrm{~mm}$ and $t$ (thickness) $=1.50 \mathrm{~mm}$. The measured true stress-strain curve from the uniaxial standard tensile test may be expressed as a power hardening law:

$$
\epsilon=\frac{\sigma}{E}+\alpha\left[\left(\frac{\sigma}{\sigma_{y s}}\right)^{n}-1\right],
$$

where $E$ is Young's modulus, $\sigma_{y s}$ is yield stress, $n$ in the strain hardening exponent and $\alpha$ is the material coefficient, all of which can be found in Table 1. The computed multiaxial stress distribution in a cracked thin plate is related to the uniaxial tensile data with the equivalent stress $\sigma_{e}$ as

$$
\sigma_{e}=\left(\frac{3}{2} \sigma_{i j}^{\prime} \sigma_{i j}^{\prime}\right)^{1 / 2}
$$

where $\sigma_{i j}^{\prime}$ is stress deviator tensor.

The loading of the cracked specimen is applied incrementally until the threshold condition of crack growth is satisfied, i.e. $(\mathrm{d} W / \mathrm{d} V)_{c}^{*}=(\mathrm{d} W / \mathrm{d} V)$ in an element ahead of the crack tip along its prospective crack path. Over a hundred load increments were found necessary before the threshold condition was met. The crack surface was then allowed to unload itself after each crack advance. Five incremental unloadings were used, resulting the development of a typical unloading zone and secondary plastic zone as depicted in Fig. 4.

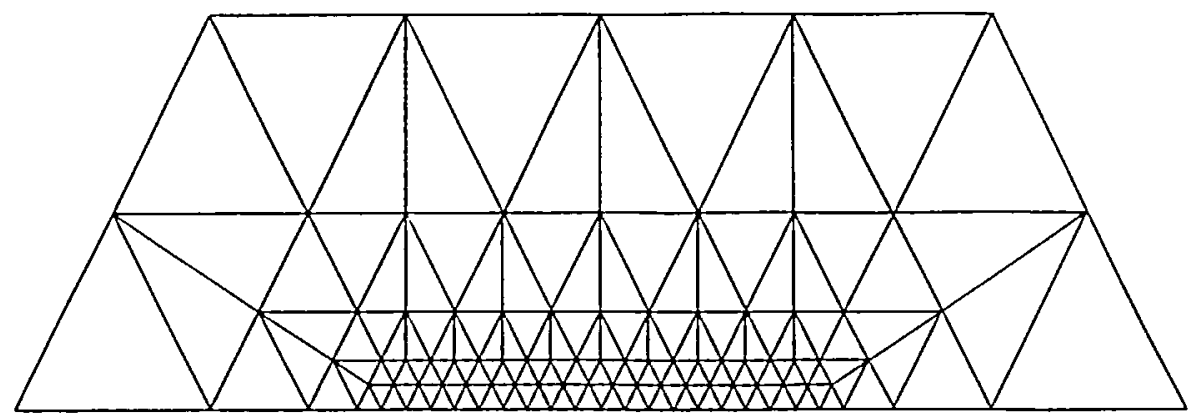

Fig. 3. Finite element representation at crack tip.

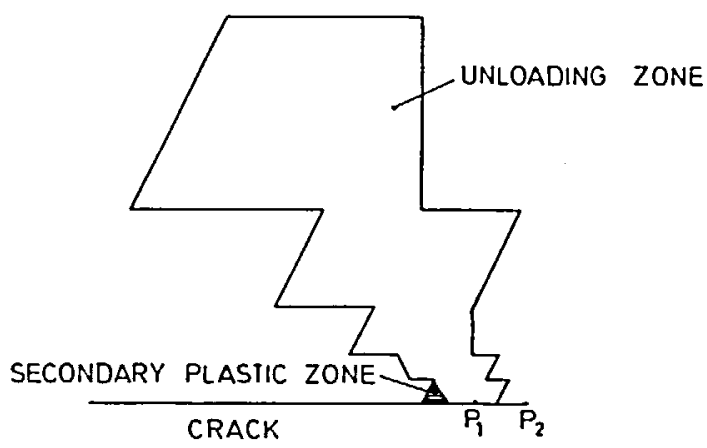

Fig. 4. Development of unloading and secondary plastic zones after a crack advance from $P_{1}$ to $P_{2}$. 


\section{EXPERIMENTS}

The tests were carried out with a universal testing machine. The specimen was in the first instance fatigue-precracked to produce the initial total crack length of $13.46 \mathrm{~mm}$. The specimen was gradually loaded incrementally to about $70 \%$ of its estimated critical load. The critical load is defined as the load at which further crack propagation will lead to global instability of the test specimen. The load increment was then substantially reduced until final rupture. The continuous growth of the crack as the specimen was being loaded was monitored with a travelling microscope at $\times 80$, which enabled the recording of the crack extension up to $0.01 \mathrm{~mm}$.

In order to aid the measurement of crack growth as well as the plastic strains developed at the crack tips, moiré and laser speckle methods were used on each side of the specimen surfaces [18]. The moiré method was used to record relatively large plastic deformation with a crossgrating frequency of about $40 \mathrm{1pm}$, while the speckle method with equivalent frequency of about $4671 \mathrm{pm}$ was chosen to measure elastic deformation field when the applied load was relatively low.

\section{DISCUSSION OF RESULTS}

The strain energy density function $\mathrm{d} W / \mathrm{d} V$ is defined as the total energy stored per unit volume of material under consideration. It may be expressed in terms of the true stress $\sigma_{i j}$ and true strain $\epsilon_{i j}$ computed from the finite element analysis as

$$
\frac{\mathrm{d} W}{\mathrm{~d} V}=\int \sigma_{i j} \mathrm{~d} \epsilon_{i j}
$$

From physical considerations, excessive change in shape or distortion in a volume element is associated with yielding, while excessive change in volume or dilatation is associated with fracture. The strain energy density may be subdivided into two parts. The term involving the dilatation energy may be evaluated by

$$
\left(\frac{\mathrm{d} W}{\mathrm{~d} V}\right)_{.}=\frac{1}{3} \int \sigma_{i i} \mathrm{~d} \epsilon_{i i}
$$

and the distortion energy by

$$
\left(\frac{d W}{d V}\right)_{d}=\frac{d W}{d V}-\left(\frac{d W}{d V}\right)_{V}
$$

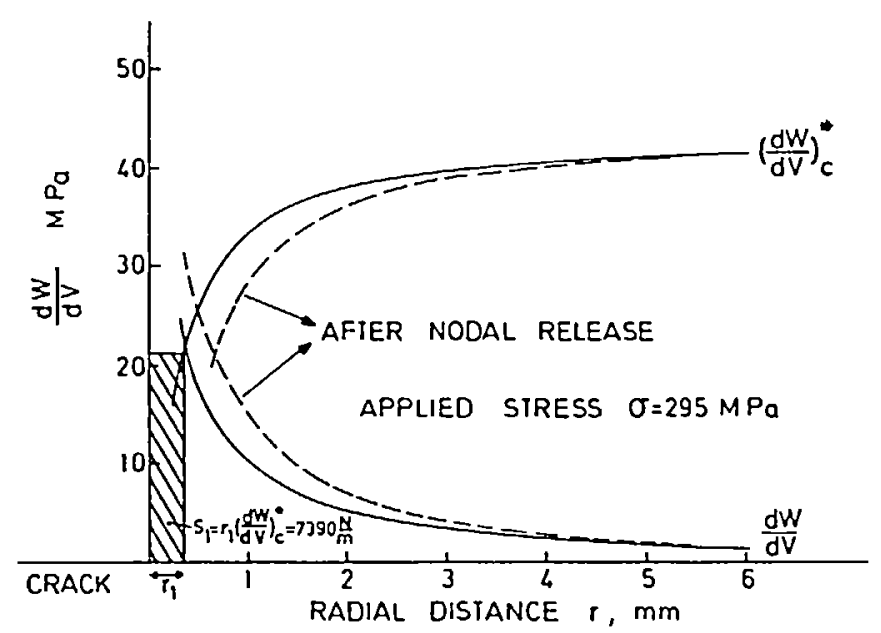

Fig. 5. Variations of strain energy density for half crack length of $a_{1}=6.7 \mathrm{~mm}$. 


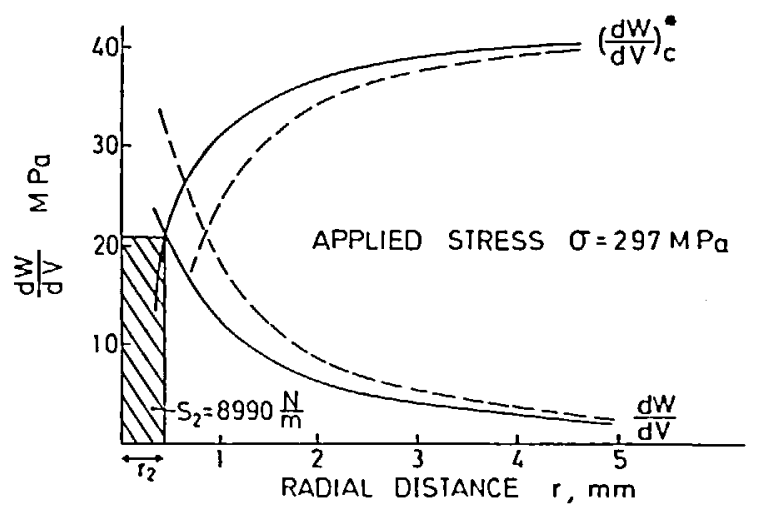

Fig. 6. Variations of strain energy density for half crack length of $a_{2}=7.05 \mathrm{~mm}$.

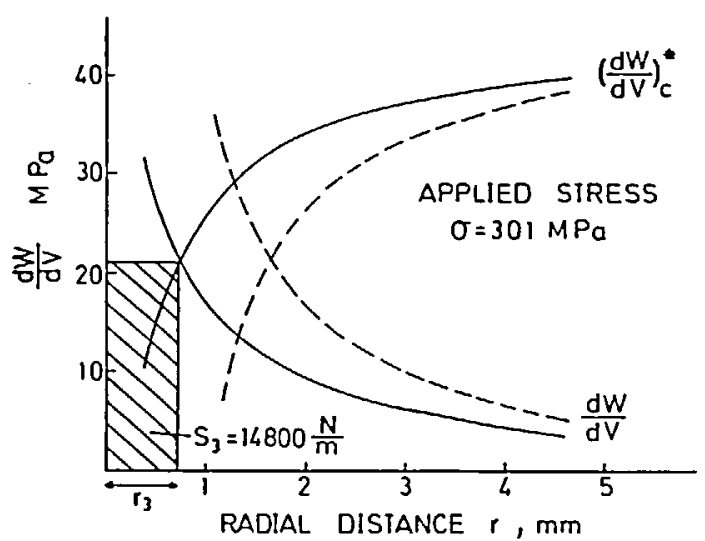

Fig. 7. Variations of strain energy density for half crack length of $a_{3}=7.48 \mathrm{~mm}$.

According to the strain energy density criterion, the onset of crack initiation and growth is postulated to occur when the strain energy density ahead of the crack tip ( $\mathrm{d} W / \mathrm{d} V$ ) is equal to the material crack growth resistance parameter $(\mathrm{d} W / \mathrm{d} V)_{*}^{*}$ defined in eqn (2). The computed crack growth results are summarized in Figs 5-9, each representing a crack increment for a total of five growth steps. It can be observed from the figures that the initial half crack length of $6.7 \mathrm{~mm}$ was extended at the applied stress of $295 \mathrm{MPa}$ to its final crack length of $11.08 \mathrm{~mm}$ at the applied stress of $306.8 \mathrm{MPa}$, resulting a total crack growth of $\Delta a=4.38 \mathrm{~mm}$. Each figure also illustrates significant crack surface unloading effects due to nodal force release after the crack growth threshold condition of $(\mathrm{d} W / \mathrm{d} V)=(\mathrm{d} W / \mathrm{d} V)_{c}^{*}$ is initially satisfied. Figure 4 depicts the unloading zone together with the development of a secondary plastic zone behind a crack tip after it has advanced from a crack location $P_{1}$ to its new location $P_{2}$.

Both the computed and experimental crack growth results against their corresponding fracture loads are illustrated in Fig. 10. Also shown in the figures are the predictions made based on an elongation failure criterion [18]. Because of the difficulties of maintaining an "absolute" symmetry of the embedded crack with respect to its center line, some deviations, although not substantial, in the crack growth measurement at its right and left tips were observed, and are illustrated in the figure. The elongation failure criterion postulates that crack initiation takes place when the tensile strain at the crack tip reaches the elongation of the material at failure under the uniaxial tensile loading.

For ease of comparison, the results shown in Fig. 10 are summarized numerically in Table 2. It can be concluded from the table that the predicted fracture loads are in excellent agreement with those determined experimentally with the maximum percentage error between the predicted and measured fracture loads being within $4.0 \%$.

One of the hypotheses made in the strain energy density criterion is related to the rate of 


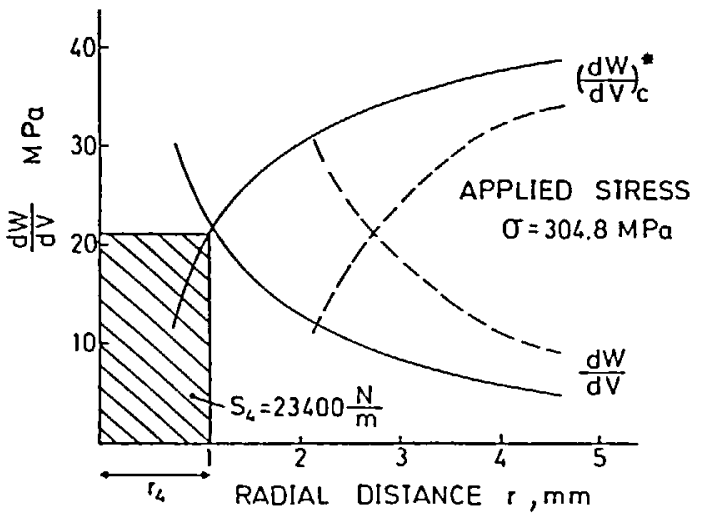

Fig. 8. Variations of strain energy density for half crack length of $a_{4}=8.18 \mathrm{~mm}$.

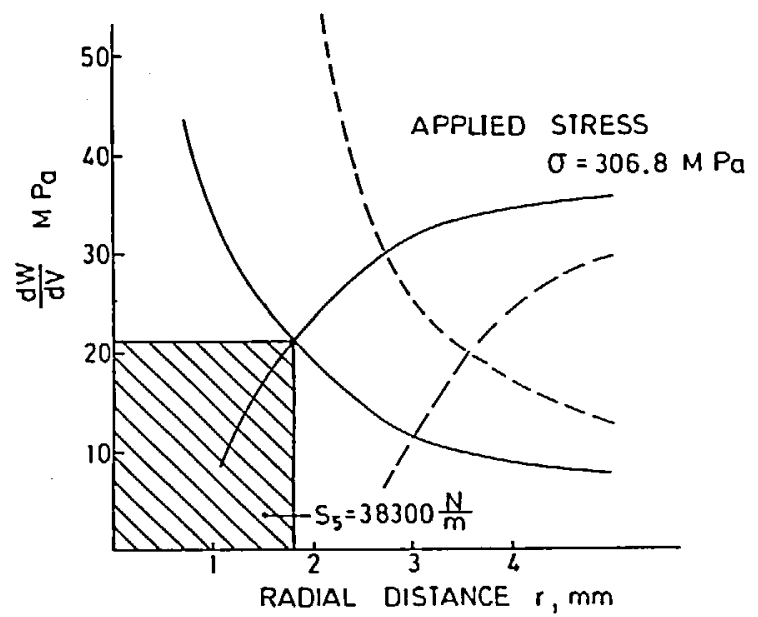

Fig. 9. Variations of strain energy density for half crack length of $a_{5}=9.28 \mathrm{~mm}$.

crack growth governed by the condition that [15]

$$
\left(\frac{\mathrm{d} W}{\mathrm{~d} V}\right)_{c}^{*}=\frac{S_{1}}{r_{1}}=\frac{S_{2}}{r_{2}}=\ldots .=\frac{S_{j}}{r_{j}}=\ldots .=\frac{S_{c}}{r_{c}}=\text { constant }
$$

where $S_{c}$ and $r_{c}$ are respectively the critical strain energy density factor and the critical crack length. Unstable crack propagation or global instability is said to occur when $S_{\mathrm{c}} / r_{\mathrm{c}}$ is reached,

Table 2. Subcritical crack growth

\begin{tabular}{|c|c|c|c|c|c|}
\hline \multicolumn{3}{|c|}{ Strain energy density criterion } & \multicolumn{2}{|c|}{ Experiment } & \multirow[b]{2}{*}{$\begin{array}{c}\text { Applied fracture } \\
\text { load differences } \\
\qquad(\%)\end{array}$} \\
\hline $\begin{array}{l}\text { Growth } \\
\text { step no. }\end{array}$ & $\begin{array}{l}\text { Applied load, } \\
\sigma(\mathrm{MPa})\end{array}$ & $\begin{array}{c}\text { Crack growth, } \\
\qquad a(\mathrm{~mm})\end{array}$ & $\begin{array}{l}\text { Applied load, } \\
\sigma(\mathrm{MPa})\end{array}$ & $\begin{array}{l}\text { Crack } \\
\text { growth, } \\
\Delta a(\mathrm{~mm})\end{array}$ & \\
\hline 1 & 295.0 & 0.35 & 300.0 & $0.3 \dagger / 0.12 \ddagger$ & 1.7 \\
\hline 2 & 297.0 & 0.43 & 309.0 & $0.38+/ 0.11 \div$ & 3.9 \\
\hline 3 & 301.0 & 0.70 & 313.6 & $0 \dagger / 0.29 \div$ & 4.0 \\
\hline 4 & 304.8 & 1.10 & 315.6 & $0.33+/ 0.29+$ & 3.4 \\
\hline 5 & 306.8 & 1.80 & 316.5 & Unstable & 3.1 \\
\hline
\end{tabular}

tLeft crack tip growth measurement.

$\ddagger$ Right crack tip growth measurement. 


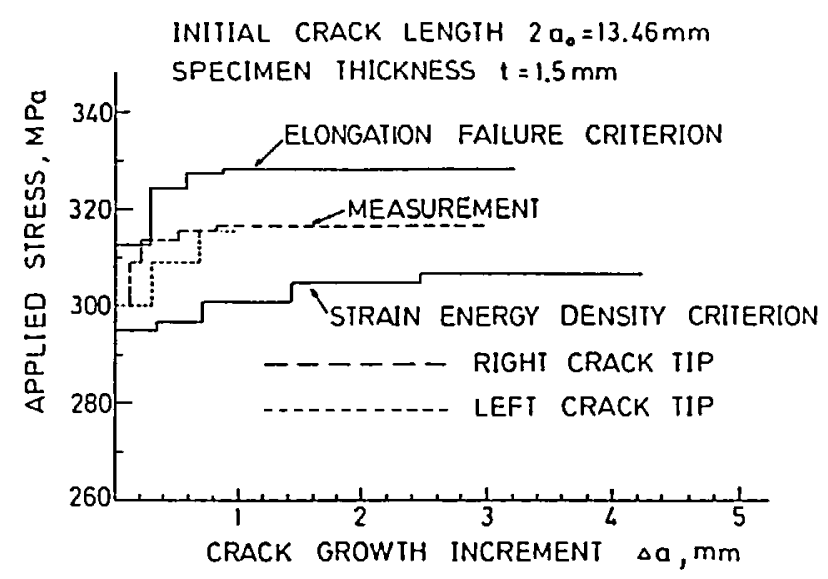

Fig. 10. Subcritical crack growth.

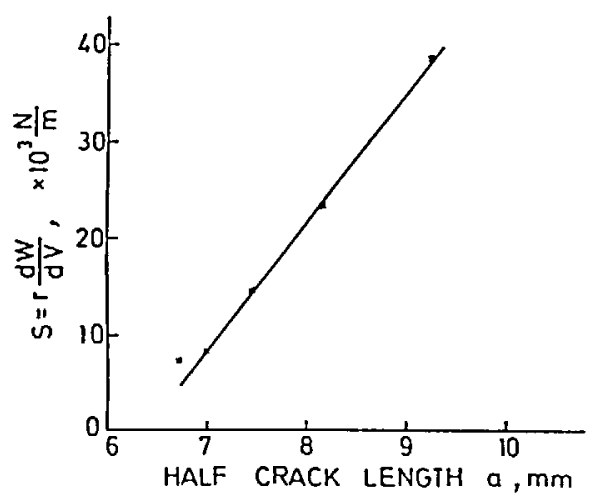

Fig. 11. Strain energy density factor vs crack length.

provided that

$$
\begin{gathered}
S_{1}<S_{2}<\ldots<S_{j}<\ldots \ldots<S_{c} \\
r_{1}<r_{2}<\ldots<r_{j}<\ldots \ldots<r_{c} .
\end{gathered}
$$

The above conditions may be verified by plotting the strain energy density factor, $S$, against crack length $a$ as shown in Fig. 11. The figure reveals the linear $S-a$ relationship, thus confirming the validity of the hypothesis that $\mathrm{d} S / \mathrm{d} a=$ constant .

\section{CONCLUSIONS}

1. The strain energy density criterion can correctly characterize the subcritical crack growth behavior of thin crack plates stressed beyond gross yielding.

2. The validity of the application of the strain energy density approach to ductile fracture studies is verified by comparing the predicted and measured fracture loads of a thin cracked plate experiencing subcritical crack growth. Excellent agreement between the predicted and measured fracture loads is attained with the maximum percentage prediction error less than $4.0 \%$.

\section{REFERENCES}

[1] J. R. Rice, A path independent integral and approximate analysis of strain concentration by notches and cracks. J. Appl. Mech. 35, 379-386 (1968).

[2] G. A. Clark, W. R. Andrews, J. A. Begley, J. K. Donald, G. T. Embley, J. D. Landes, D. E. MícCabe and J. H. Underwood, A procedure for the determination of ductile fracture toughness values using $J$-integral techniques. J. Testing Eval. 7, 49-56 (1979). 
[3] A. A. Wells, Application of fracture mechanics at and beyond general yielding. Br. Welding J. 563-570 (1963).

[4] F. M. Burdekin and D. E. W. Stone, The crack opening displacement approach to fracture mechanics in yielding mechanics. J. Strain Anal. 2, 145-153 (1966).

[5] P. C. Paris, H. Tada, A Zahoor and H. Ernst, The theory of instability of the tearing mode of elastic-plastic crack growth. ASTM STP 668, 5-36 (1979).

[6] H. Tokahashi, M. A. Khan and M. Suzuki, A simple test method for the evaluation of tearing modulus. J. Testing Eval. 9, 14-23 (1981).

[7] D. G. H. Latzko, Post-Yicld Fracture Mechanics. Applied Science Publishers, London (1979).

[8] A. R. Luxmoore, M. F. Light and W. T. Evans, A comparison of energy release rate. the $J$-integral and crack tip displacements. Int. J. Fract. 13, 257-259 (1977).

[9] M. F. Light and A. R. Luxmoore, A numerical investigation of post-yield fracture. J. Sirain Anal. 12, 293-304 (1977).

[10] C. A. Griffiths, Elastic plastic fracture toughness, a comparison of $J$-integral and crack opening displacement characterization. ASME Paper No. 75-PVP-38 (1975).

[11] A. D. Batte, IV. S. Blackburn, A. Elsender, T. K. Hellen and A. D. Jackson, A comparison of the $J^{*}$ integral with other methods of post-yield fracture mechanics. Int. J. Fract. 21, 49-66 (1983).

[12] G. C. Sih, Some basic problems in fracture mechanics and new concepts. Engng Fract. Mech. 5, 365-377 (1973).

[13] G. C. Sih and B. MacDonald, Fracture mechanics applied to engineering problems-strain energy density fracture criterion. Engng Fract. Mech. 6, 361-386 (1974).

[14] G. C. Sih and E. Madenci, Fracture initiation under gloss yielding: strain energy density criterion. Engng Fract. Mlech. 18, 667-677 (1983).

[15] G. C. Sih and E. Madenci. Crack growth resistance characterized by the strain energy density function. Engng Fract. Mech. 18, 1159-1171 (1983).

[16] R. Hill. Some basic principles in the mechanics of solids without a natural time. J. Mech. Phys. Solids 7, 209225 (1959).

[17] R. M. McMeeking and J. R. Rice, Finite element formulations for problems of large elastic-plastic deformation. Int. J. Solids Struct. 11, 601-616 (1975).

[18] Jilin Xu. Analysis of stable crack growth for plane stress by finite element method. Acta Mcch. Sin. 3, 272-279 (1982). 